Sólo cuando la voluntad jurídica deje de actuar en la medida prevista, ocurre el proceso como instrumento de producción que llamaremos subsidiario.

El proceso actúa en vez de la voluntad jurídica obediente. Su destino es elaborar por acto de la autoridad, una voluntad jurídica suceptible de reemplazar a la voluntad jurídica obediente. La sentencia actúa en lugar del deudor, del padre o del arrendatario omiso en el cumplimiento de sus obligaciones.

El proceso asegura la vigencià de la lex continuitatis, del derecho, porque si la voluntad jurídica omisa pudiera interrumpir la vigencia de dicha ley, los fines del derecho se desnaturalizarían. El aseguramiento de la continuidad no es, pues, inherente a la esencia, pues la continuidad se realiza por la voluntad jurídica obediente. Es inherente a la función, pues está en la naturaleza de esta última, que el derecho no se desnaturalice por la desobediencia.

Hay, además, casos en los que el derecho se frustra a pesar del proceso. Así ocurre, por ejemplo, cuando el acreedor renuncia a demandar a sua deudor y prefiere perder el crédito; o cuando cumplido el proceso, la sentencia no puede cumplirse por insolvencia del obligado.

El proceso es una forma de asegurar la unidad del derecho y su lex continuitatis. Pero no es la única; y comparado con la realización espontánea del derecho, con la obediencia natural a la ley que se adquiere por largos y pacientes instancias de educación del pueblo, el proceso no es ni siquiera el mas importante instrumento de producción jurídica.

El optimus del derecho no es el proceso, sino la realización espontánea. Si todos los contribuyentes, si todos los padres, si todos los arrendatarios debieran ser demandados judicialmente para cobrar el impuesto, mantener a los hijos o reintegrar la propriedad, la maquinaria estatal saltaría hecha pedazos.

Pero fracasado el optimus, se acude al subrogado o sustitutivo. El sustitutivo es el proceso. $Y$ es, necesariamente, un sustitutivo imperfecto. Todo proceso, por excelente que sea, lleva consigo una medida de injusticia que no repara la sentencia. El triunfador siempre conserva entre las manos, luego del proceso, una cantidad de injusto dolor que no resulta nunca reparada.

Esto no es, ciertamente, lógica jurídica; pero es experiencia jurídica de la que en ningún instante; y perdónese la insistencia! puede desentenderse la ciencia conceptual del derecho.

COMENTÁRIO DO $\S 10^{\circ}$ DO ART. 153

\section{DA CONSTITUIÇÃO}

\section{Darcy Azambuja}

1. - Em face do disposto no $\$ 10^{\circ}$ do art. 153 da Constituição de 18 de setembro de 1946, estão revogados os preceitos legislativos anteriores, que vedavam ao estrangeiro ser acionista de emprêsas que explorem, dentro ou fora da faixa de 150 quilômetros ao longo da fronteira, de que cuida o decreto-lei n. ${ }^{\circ} 1.968$, de 17 de janeiro de 1940: a) a indústria da refinação do petróleo importado ou de produção nacional; ou b) jazidas minerais no Brasil; e, em caso afirmativo,

2. - Independentemente de regulamentação legal, podem ditas emprêsas admitir, desde já, acionistas estrangeiros?

3. - A lei ordinária poderá restringir ou limitar a participação de estrangeiros nessas emprêsas?

4. - O acionista estrangeiro deve residir no Brasil?

Quanto ao item primeiro, cumpre examinar preliminarmente a legislação anterior à atual Constituição.

A Constituição de 1891, em seu texto primitivo, dispunha apenas, em alínea do $\$ 17$, do art. 72 :

“As minas pertencem ao proprietário do solo, salvas as limitações que forem estabelecidas por lei, a bem da exploração dêste ramo de indústria".

Com a reforma de 1925-26, introduziu-se a restrição da letra $b$ do mesmo parágrafo:

"As minas e jazidas minerais necessárias à segurança nacional e as terras onde existirem não podem ser transferidas a estrangeiros".

Êsse preceito, tradicional em nosso direito, tem sofrido ampliação nas leis fundamentais posteriores. No texto, assim reformado, 
da de 1891 , somente se proibia que pertencessem a estrangeiros as minas e jazidas necessárias à segurança e defesa nacionais.

Dispondo sôbre o aproveitamento industrial das minas, jazidas minerais, águas e energia hidráulica, a Constituição de 1934 determinou, no $\$ 1 .^{\circ}$ do art. 119:

"As autorizações oụ concessões serão conferidas exclusivamente a brasileiros ou a emprêsas organizadas no Brasil, etc."

Omitiu-se, assim, a distinção entre minas e jazidas necessárias à segurança nacional e as que não o fôssem, declarando-se que tôdas sòmente poderiam ser exploradas por brasileiros, isto é, pessoas físicas brasileiras ou pessoas jurídicas brasileiras, pois a tanto equivale a expressão "emprêsas organizadas no Brasil".

A Constituição de 1937 , dentre as poucas disposições suas postas em vigor, continha a do $\$ 10^{\circ}$ do art. 143 :

"A autorização só será concedida a brasileiros ou emprêsas constituídas por acionistas brasileiros..."

Posteriormente, pela lei constitucional n. 6 , de 13 de maio de 1942, seria aberta uma exceção para as quedas dágua e outras fontes de energia hidráulica.

Os decretos-leis subseqüentes, como o de n. 1.985 , de 29 de janeiro de 1940 e de n. 2.778 , de 12 de novembro de 1940 , dispondo sôbre a indústria de mineração, regulamentaram o texto constitucional acima citado.

Foi, pois, a Constituição de 1937 que proibiu aos estrangeiros serem acionistas das emprêsas brasileiras de mineração. Na vigência da de 1934 tal proibição não existia. Exigia ela sòmente que as emprêsas fôssem organizadas no Brasil, isto é, integralmente sujeitas ao direito brasileiro, por serem brasileiras. Antes de 1937 nenhum texto legal continha a restrição, com aquela amplitude que veio golpear profundamente, pela ausência do capital estrangeiro, o aproveitamento de nossas riquezas minerais. Tão grave foi o golpe, que a lei constitucional n. ${ }^{\circ}$, de 1942 , teve que excetuar do preceito jacobino as emprêsas exploradoras da energia hidráulica, sob pena de paralisar a indústria da maioria das cidades do país.

A Constituição de 18 de setembro de 1946 restabeleceu, também neste particular, o regímen legal anterior, dispondo no $\$ 1 .^{\circ}$ do art. 153:

"As autorizações ou concessões serão conferidas exclusimente a brasileiros ou a sociedades organizadas no país, etc”.
E a reprodução ipsis verbis do texto da Constituição de 1934 com a única substituição de um vocábulo: emprêsa por sociedade.

Bastaria, por certo, êste ligeiro retrospecto para demonstrar que - legislador constituinte de 1946 quis deliberadamente alterar regra escrita na Carta de 1937, retornando à orientação tradicional esposada pela Constituição de 1934. Absolutamente temerário, e injusto, seria supor que, em matéria de tal relevância, pelos debates que suscitou e pela repercussão que teve a proibição contida na Carta de 37, fôsse o seu texto alterado por simples inadvertência. Se nela vinha estatuído que as emprêsas, para explorar as jazidas minerais, haveriam de ser "constituidas por acionistas brasileiros", e na atual se exige apenas que sejam "organizadas no pais", evidente se torna ter sido dispensada a exigência anterior. Parece que a nenhum intérprete ocorreria sustentar que a expressão "sociedades organizadas no pais" queira significar "sociedades constituidas por acionistas brasileiros".

Sociedade organizada no país quer dizer simplesmente pessoa jurídica de direito brasileiro, pessoa jurídica sòmente regida pelo direito brasileiro - ensina Pontes de Miranda, comentando o texto idêntico da Constituição de 1934. Para que isso se dê, não é necessário que a sociedade ou emprêsa seja constituída exclusivamente por brasileiros; podem ser estrangeiros todos os associados. Desde que ela se organize no Brasil, é brasileira, está sujeita sòmente à lei brasileira.

E assim está cumprida a exigência constitucional, pois o que esta visa é conceder sòmente a brasileiros, pessoa física ou jurídica, a exploração das riquezas minerais do país. Ou melhor, o fim evidente da regra constitucional é duplo: primeiro, incrementar, estimular o aproveitamento dos recursos minerais existentes no país; segundo, confiar a exploração dêles a brasileiros, para melhor fiscalizar êsse ramo de indústria, que interessa diretamente a defesa nacional.

A Constituição de 1937 e a legislação sob ela promulgada, atingia sòmente o segundo objetivo, e prejudicou o primeiro, pois impediu a cooperação do capital estrangeiro. Dado o fato, certo e sabido, da absoluta insuficiência do capital nacional para a indústria da mineração, que exige comumente somas enormes e vasto aparelhamento técnico, a proibição anterior teve como resultado paralisar pràticamente a mineração, mesmo com a concessão aberta em favor das minas já em lavra (Const. de 1937, art. $143 \S 4 .^{\circ}$ ).

O legislador constituinte de 1946, bem avaliando a gravidade do problema e as necessidades urgentes do Brasil, em boa hora voltou ao regímen da Constituição de 1934 , permitindo a participação do capital estrangeiro na indústria da mineração, desde que o faça através de emprêsas nacionais. 
A essa mesma conclusão leva a interpretação sistemática, o estudo comparativo de outras disposições similares da Constituição atual.

Quando os elaboradores da Constituição querem vedar ou limitar, realmente, a participação de estrangeiros em certas emprêsas, o texto é expresso e rigoroso, como se dá com o art. 160 que proíbe a sociedades anônimas por açóes ao portador e a estrangeiros a propriedade de emprêsas jornalísticas e de radiodifusão, e exige que a responsabilidade intelectual e administrativa seja exclusivamente confiada a brasileiros.

Do mesmo modo é taxativa nossa atual Constituição quando, no art $180 \& 11^{\circ}$, determina que nas zonas consideradas por lei indispensáveis à segurança nacional, o capital e o trabalhador nacionais predominarão.

Igualmente foi explícita no art. 155, estatuindo que a navegação de cabotagem é privativa dos navios nacionais, que seus armadores, proprietários e comandantes devem ser brasileiros, bem como dois terços pelo menos de seus tripulantes.

Sempre, pois, que a Constituição quer proibir ou restringir a participação de estrangeiros em determinada indústria ou atividade, não o faz implicitamente, mas expressamente; nem poderia ser de outro modo, de vez que a boa técnica legislativa ensina que as restrições e excessões hão de vir explícitas no texto, porque não se presumem.

Resumindo, as premissas são as seguintes:

A Constituição de 1934 dispunha que as emprêsas de mineração fôssem organizadas no Brasil, isto é, fôssem brasileiras, e tanto sua interpretação como a legislação ordinária permitiam que ditas emprêsas admitissem acionistas estrangeiros.

A Constituição de 1937 determinou que essas emprêsas fôssem "constituídas exclusivamente por brasileiros".

A Constituição de 1946 restabeleceu o texto da de 1934, exigindo sòmente que tais emprêsas sejam "organizadas no país".

A atual Constituição sempre que entendeu proibir ou restringir a participação de estrangeiros em determinadas emprêsas brasileiras o fêz expressa e categòricamente. A conclusão se impõe por si mesma: A atual Constituição permite a participação de acionistas estrangeiros nas emprêsas de mineração.

$\mathrm{E}$ é fácil demonstrar que não sòmente permite como também tem por fim o preceito constitucional estimular, atrair a participação de acionistas estrangeiros nessas emprêsas.

De fato. O elemento histórico, os trabalhos parlamentares têm diminuído de valor na hermenêutica, porque as leis devem ser interpretadas principalmente para adaptá-las à realidade social. Sôbre tudo quando se trata de leis antigas, o "pensamento do legisldor" pode não mais coincidir com as exigências atuais da sociedade, mas a lei deve continuar a viver.
Revista da Faculdade de Direito de Pôrto Alegre

"Sucede o contrário com a lei nova e as circunstâncias que rodearam a elaboração do texto persistem ainda: atuam os mesmos fatôres sociais, perduram, para a coletividade, os mesmos objetivos econômicos, as aspirações justas, os hábitos adquiridos, os usos e costumes" (Carlos Maximiliano - Hermenêutica e Aplicação do Direito. pág. 152).

Neste caso, que é o da atual Constituição, o fim que o legislador teve em mira, exposto nos trabalhos parlamentares, é elemento importante para a exata interpretação e aplicação do texto.

O anteprojeto discutido na Comissão Constitucional, èm 1946, era semelhante ao texto atual:

“As autorizações ou concessões serão conferidas exclusivamente a brasileiros ou a emprêsas organizadas no Brasil, ressalvada ao proprietário preferência na exploração ou coparticipação nos lucros".

Vê-se que, quanto à participação de estrangeiros nas emprêsas de mineração, o anteprojeto era idêntico ao texto hoje vigente. A êsse dispositivo foram apresentadas, no seio da Comissão, algumas emendas, uma das quais visava exatamente proibir que estrangeiros fizessem parte dessas emprêsas. Foi a emenda do deputado Mario Masagão, assim redigida:

“As autorizações serão conferidas exclusivamente a brasileiros ou emprêsas por êles organizadas, ressalvada ao proprietário etc. etc."

O deputado professor Hermes Lima, relator da Sub-Comissão que elabora o anteprojeto, assim o defendeu:

"Sr. Presidente, a Sub-Comissão, ao redigir o dispositivo, teve em mira estatuir que as autorizações ou concessões pudessem ser conferidas a brasileiros ou a emprêsas organizadas no Brasil, de que pudessem participar capitais estrangeiros. Se a Comissão entende que a expressão "emprêsas organizadas no Brasil" não é suficiente para assegurar a participação de capitais estrangeiros, o dispositivo, naturalmente, deve ser modificado, porque o intuito da. subcomissão foi, por essa fórmula, assegurar tal participa$c ̧ \tilde{a} o$.

Parece, entretanto, que, retirado o advérbio "exclusivamente", a expressão "autorização", nos têrmos em que é concedida, abrange brasileiros e emprêsas organizadas 
no Brasil com capital estrangeiro. Não há nenhum impedimento de que capitais estrangeiros organizem no Brasil sociedade para obter a concessão e explorar jazidas minerais, "minas e quedas dágua. Julgo que o artigo é, portanto, claro".

Incisivo foi, também, o parecer de outro ilustre jurista, membro da Comissão, o deputado Prado Kelly:

"Sr. Presidente, o $\$ 10^{\circ}$ do art. 10 do Projeto reproduz o que já diśpunha o $\$ 10^{\circ}$ do art. 119 da Constituição de 1934. Estou de inteiro acôrdo com o projeto, e vou justificar meu voto.

No ponto que suscitou dúvidas ao meu prezado amigo, sr. Deputado Eduardo Duvivier, isto é, a cláusula "emprêsas organizadas no Brasil", e que também é objeto de emenda do erudito professor Mario Masagão, não creio que procedam as críticas, porque a Constituição de 34 levou a bases extremas a proteção nacionalista. Entretanto, não estabeleceu nenhuma condição quanto à nacionalidade dos sócios das emprêsas organizadas no Brasil. E assim procedeu por motivo óbvio: é que estas emprêsas, desde que organizadas aqui, passam a ser pessoas jurídicas de nacionalidade brasileira.

O que cumpria evitar é que sociedades com sede no estrangeiro, cuja direção não pudesse ser fiscalizada pelas autoridades brasileiras, e tivessem fôro também em outro país que não o nosso, viessem obter autorização ou concessão para a exploração da propriedade prevista no artigo.

Por êstes motivos entendo que o interêsse nacional já está suficientemente acautelado com a redação dada ao $\S 1 .^{\circ}$ do art. 10 do Projeto.

A questão de se eliminar a cláusula "exclusivamente" é para mim despicienda. Com ou sem advérbio, o pensamento só pode ser restritivo".

Posta em votação e emienda do deputado Mario Masagão, que exigia nacionalidade brasileira aos sócios das emprêsas de mineração, foi a mesma rejeitada, como tudo se vê no "Diário da Assembléia" de 16 de maio de 1946, pág. 1.865.

Não poderia ser mais claramente expresso o pensamento do legislador constituinte; os dois ilustres juristas frisaram insistentemente que o texto aprovado tem por objetivo permitir a participação do capital estrangeiro nas emprêsas que exploram minas e jazidas minerais do país.
Assim, todos os métodos de interpretação do texto constitucional conduzem à mesma conclusão, e, conseqüentemente, é afirmativa a resposta do primeiro item da consulta.

Em face do disposto no $\S 10^{\circ}$ do artigo 153 da Constituição atual, estão revogados os preceitos legais anteriores que vedavam ao estrangeiro ser acionista de sociedades que explorem a incústria de mineração no Brasil.

Esta é a inimpugnável solução geral ao quesito formulado, pois, em face do texto constitucional, nenhuma restrição existe mais ao estrangeiro nas emprêsas de mineração.

No entanto, o item se desdobra e introduz um elemento novo, quando alude à faixa de 150 quilômetros ao longo da fronteira, de que cuida o decreto-lei n. ${ }^{\circ} 1.968$, de 17 de janeiro de 1940.

Ao tratarmos, adiante, do item terceiro, examinaremos mais de perto o assunto, mas, para não deixar em suspenso ou incompleta a resposta do item primeiro, convém adiantar desde já o corolário da argumentação a ser expendida.

A atual Constituição não proíbe a participação de acionistas estrangeiros em emprêsas que explorem a indústria de refinação de petróleo importado ou de produção nacional nem nas que explorem jazidas minerais, estejam elas situadas ou não na referida faixa de 150 quilômetros. Não proíbe, mas limita essa participação, se ditas emprêtsas estiverem localizadas dentro da faixa de fronteira. E' uma restrição imposta não sòmente às emprêsas de refinação e mineração, mas a qualquer outra indústria ali situada.

Com efeito, o $\$ 10^{\circ}$ do art. 180 da Constituição dispõe:

“A lei especificará as zonas indispensáveis à defesa nacional, regulará a sua utilização e assegurará, nas indústrias nelas situadas, a predominância de capitais e trabalhadores brasileiros.

Combinando o texto acima com o do decreto n. ${ }^{0} 1.968$ de 17 de janeiro de 1940, conclui-se que em qualquer indústria e, portanto nas emprêsas de mineração e refinação de petróleo situadas na faixa da fronteira, as ações com direito a voto serão nominativas e deverão pertencer, na maioria, a brasileiros.

A resposta ao item segundo, sòmente pode ser afirmativa, como corolário de tudo que acima ficou exposto.

A Constituição entra imediatamente em vigor. Salvo quando ela própria declara expressamente que tal ou tal preceito será aplicado na forma que a lei determinar, se ainda não houver lei a respeito, é que fica em suspenso a execução material, o modus faciendi até que o legislador providecie. Mas o direito é adquiridó desde o momento da promulgação.

$5-$ R. F. D 
Ora, no caso em aprêço, o texto constitucional é categórico e não subordinou sua aplicação a uma lei por fazer. Ou melhor: Tôda a matéria contida no art. 153 da Constituição, referente a minas, jazidas, quedas dágua, etc., bem como à sua exploração, já está regulada no Código de Minas e outros decretos. Sòmente, nessa legislação, estão revogadas tôdas as disposições que proibiam aos estrangeiros ser acionistas de emprêsas de mineração, e continuam em vigor as demais Não há, pois, que aguardar regulamentação para a participação daqueles capitais, é desde a data da promulgção da Constituição que ditas emprêsas podem admitir acionistas estrangeiros.

$\mathrm{O}$ item terceiro indaga se a lei ordinária poderá restringir ou limitar a participação de estrangeiros nas emprêsas de mineração.

As constituições traçam regras amplas, destinadas a perdurar sôbre as modificações freqüentes e às vêzes rápidas do meio social; lançam as bases da organização nacional, que as leis completam e afeiçoam às necessidades e circunstâncias ocorrentes. Ao legislador fica sempre uma autonomia maior ou menor na aplicação daquelas regras fundamentais, desde que não as infrinjam, deturpando-lhes o sentido ou impedindo-lhes a execução.

Vimos, ao tratar do item primeiro, que o fim colimado pela Constituição, no $\$ 10^{\circ}$ do art. 153 , foi atrair capitais estrangeiros para o aproveitamento efetivo de nossas riquezas minerais, dada a insuficiência de capitais brasileiros, nesse particular ainda mais escassos do que em outros campos da nossa economia.

Assim sendo, a lei ordinária que restringisse ou limitasse a participação dêsses capitais estaria, pelo menos, dificultando a realização do objetivo que a Constituição visou atingir. Não seria manifestamente inconstitucional, mas não estaria plenamente conforme a Constituição.

Neste particular, a discussão e votação do $\$ 1 .^{\circ}$ do art. 153 no plenário da Assembléia Constituinte não deixaram dúvidas. Ao citado parágrafo, tal como está redigido, foram apresentadas duas emendas, uma pelo deputado Aliomar Balieiro e outra pelo deputado Altamiro Requião.

A última propunha a seguinte redação:

"As autorizações ou concessões serão conferidas exclusivamente a brasileiros ou a emprêsas organizadas no país, nas quais a direção pertença a brasileiros, detentores, pelo menos, de dois terços do capital, etc. etc."

A do deputado Aliomar Balieiro era idêntica; apenas resumia a exigência de dois terços do capital brasileiro para a simples maioria. Ambas pretendiam, pois, limitar a participação do capital estrangeiro e restringi-lo fora da direção das emprêsas, e foram defendidas por seus autores.

O deputado Hermes Lima defendeu o projeto dizendo, entre outras coisas:

"Sr. Presidente, a Comissão é contrária à aprovação da emenda do deputado Aliomar Baleiro. Mantém o texto do projeto, que é liberal, e o faz em virtude das razões já aqui explanadas longamente em discussões que visavam o mesmo assunto. $\mathrm{O}$ argumento do nobre deputado de que o capital estrangeiro sempre entrou no país, é verdadeiro. Deve-se assinalar, porém, que as restrições que a pareceram são recentes na vida constitucional e legal do país. O capital estrangeiro sempre veio para o Brasil porque não existiam essas restrições. $O$ argumento de $S$. Excia. é, pois, contrário ao ponto de vista que sustento".

Teceu o ilustre professor outras considerações, opinando também pela rejeição da segunda emenda. Postas em votação, foram efetivamente rejeitadas pela Assembléia. E esta o fêz perfeitamente esclarecida pelos brilhantes debates travados. Rejeitando-as, adotou o ponto de vista da Comissão de Constituição: de que nenhuma restrição devia ser oposta à participação do capital estrangeiro nas emprêsas de mineração aqui organizadas.

Parece, pois, que enquanto perdurarem os motivos determinantes da regra constitucional, não será lícito ao legislador ordinário restringir a colaboração dos estrangeiros no aproveitamento dos recursos minerais do país e nas suas fontes de energia hidráulica.

Êsses motivos - escassez de capital nacional e de técnicos criaram para o Brasil a situação de proprietário paupérrimo de minas riquíssimas. Tão cedo ela não se modificará, e não se modificará sem a cooperação do capital estrangeiro.

Tal é o fim, o objetivo do preceito constitucional; não é de esperar as leis ordinárias lhe entravem a consecução.

De resto, como já se frisou neste parecer, a orientação da atual Constituição é liberal e tende a sanar os males que o jacobinismo econômico e político havia criado. Ainda a propósito do assunto versado no item em aprêço, a comparação dos textos constucionais anteriores com o atual é perfeitamente elucidativa.

Assim, a Constituição de 1934 dispunha no art. $119 \S 4 .^{\circ}$ :

"A lei regulará a nacionalização progressiva das minas, jazidas minerais e quedas dágua ou outras fontes de energia hidráulica, julgadas básicas ou essenciais à defesa econômica ou militar do país".

A de 1937 foi mais longe, determinando, no art. 144:

"A lei regulará a nacionalização progressiva das minas, jazidas minerais e quedas dágua ou outras fontes de 
energia, assim como das indústrias consideradas básicas ou esesnciais à defesa econômica ou militar do país”.

Com o vocábulo nacionalização, ora se queria dizer "estatização", apropriação pelo Estado, ora proibição de capital estrangeiro. Em virtude das discussões havidas no seio da Comissão de Constituicãa e no plenário, a Assembléia suprimiu a exigência da nacionalização progressiva, as restrições possíveis à participação de capitais estrangeiros, salvo a restrição única que veremos adiante.

A atual Constituição saiu escoimada dos exageros das anteriores, sem contudo deixar desarmado o Estado em face de possíveis emergências, pois contém um preceito geral e eficaz, em seu artigo 146:

"A União poderá, mediante lei especial, intervir no domínio econômico e monopolizar determinada indústria ou atividade. A intervenção terá por base o interêsse público e por limite os direitos fundamentais assegurados nesta Constituição."

Evidencia-se, dêsse modo, o espírito liberal das nossas instituições acolhendo a cooperação honesta do capital estrangeiro, atraindo-o com largas garantias do direito de propriedade, sem descurar do interêsse público.

O mesmo se verifica em relação a outros assuntos, como, por exemplo, o referente a bancos e companhias de seguros, à revalidação de diplomas, etc.

Não é, pois, necessário alongar-se muito o intérprete para apreender o objetivo dos preceitos examinados. Tôdas as restrições gerais anteriormente levantadas contra o capital estrangeiro nas emprêsas de mineração e similares foram derrogadas pelo tex to vigente.

Cumpre, no entanto, para completa delimitação constitucional e legal do assunto, aludir a uma restrição de carácter especial, referente à participação de capitais estrangeiros, que pode atingir as emprêsas de mineração. Não as atinge, porém, por serem emprêsas de mineração, e sim ratione loci, isto é, em razão do local onde operem.

Com efeito, a Constituição Federal, em seu art. 180, dispõe:

"Art. 180. - Nas zonas indispensáveis à defesa do pais, não se permitirá, sem prévio assentimento do Conselho de Segurança Nacional.

$$
\text { I. }-\ldots \ldots \ldots \ldots \ldots
$$$$
\text { II. }-\ldots \ldots \ldots \ldots \ldots
$$

III. - O estabelecimento de quaisquer indústrias que interessem à segurança do país.
\$1.? - A lei especificará as zonas indispensáveis à defesa nacional, regulará a sua utilização e assegurará, nas indústrias nelas situadas, a predominância de capitais $e$ trabalhadores brasileiros."

Determina, pois, a Constituição que a lei ordinária especifique quais as zonas do território brasileịo que são consideradas indispensáveis à segurança nacional e que qualquer indústria aí situada. há de ter maioria de capitais e trabalhadores brasileiros.

O decreto-lei n. ${ }^{\circ} 1.968$, de 17 de janeiro de 1940 , regulou a concessão de terras, vias de comunicação e o estabelecimento de indústrias na faixa de fronteira, de acôrdo com a Constituição de 1937, art. 165.

A atual Constituição não contém mais o dispositivo das duas anteriores sôbre a faixa de fronteira, mas declara que a lei especificará as zonas indispensáveis à defesa hacional, em seu art. $180, \S 1 .^{\circ}$

E' de se perguntar se a faixa de 150 quilometros a que se refere decreto-lei acima citado pode ser considerada com "zona indispensável à defesa nacional" de que cuida o $\$ 10^{\circ}$ do art. 180 .

Parece deva ser afirmativa a resposta, apesar de aquêle decreto năo forneça elementos cabais. Numa interpretação ampla, a faixa de fronteira, objeto da regulamentação, merece ser considerada como a zona indispensável à defesa nacional, que a Constituição vigente mandou fôsse especificada por lei ordinária. Do fato de a Constituicãa de 1946 dizer - que "a lei especificará" aquelas zonas, não se conclui forçosamente que o já disposto por lei anterior esteja revogado por não declarar ser a faixa de fronteira a zona indispensável à defesa nacional. Apenas, o constituinte de 1946 preferiu deixar à lei ordinária a especificação que as Constituições de 1934 e 1937 fizeram expressamente.

Isto pôsto, admitida como zona indispensável à defesa nacional a faixa de 150 quilômetros ao longo da fronteira, e os portos marítimos situados nessa faixa, qualquer indústria aí localizada deverá ter maioria de capital e trabalhadores brasileiros.

Os arts. 36 e 37 daquele decreto abriam uma exceção para as indústrias já ali estabelecidas e para os estrangeiros que já explorassem estabelecimentos de indústria na data da sua promulgação. Essas exceções eram inconstitucionais em face do art. 165 da própria Carta de 1937 , e continuam a ser diante do $\$ 1 .^{\circ}$ do art. 180 da atual Constituição.

Dizendo aquêle decreto estarem incluídos na faixa da fronteira os portos marítimos "existentes nessa faixa", é de se concluir as fronteiras a que êle se refere são sòmente as terrestres e não as marítimas, pois do contrário todos os portos estariam nela situados, de vez que não possui o Brasil mares interiores. Conseqüentemente, a extensão 
de 150 quilômetros, para os portos marítimos, há de ser contada sôbre o litoral a partir do porto extremo dos limites nacionais ao norte e ao sul.

Resumindo: a única restrição imposta atualmente às emprêsas de mineração decorrerá de estarem localizadas na faixa de fronteira, não por serem emprêsas de mineraçã̃o, e sim por serem indústria ali situada.

Fora dêsse caso, a lei ordinária não pode opor outras restrições à admissão de sócios estrangeiros nas emprêsas aludidas, pois, como ficou demonstrado, o texto constitucional vigente tem por fim exatamente atrair êsses capitais. Se o fizesse, antes que o Brasil não mais necessitasse dêles ou sem que graves exigências da defesa nacional assim aconselhassem, o legislador estaria contrariando e mesmo anulando o objetivo colimado pela Constituição. Brasil.

$O$ item quarto indaga se o acionista estrangeiro deve residir no

A resposta a êste está contida na do item anterior. Além da restrição apontada, que decorre de estar a indústria situada em zona considerada essencial à defesa nacional, nenhuma outra a Constituição vigente consignou às emprêsas de mineração.

E a de residência do acionista estrangeiro no Brasil seria a menos plausível. Concedendo a exploração de minas, jazidas, etc., sòmente a emprêsas organizadas no Brasil, visou a Constituição assegurar a fiscalização dos seus serviços e operações sem possibilidade de atrito com potências estrangeiras.

Brasileira sendo a emprêsa, sujeita está integralmente e exclusivamente ao direito brasileiro, pouco importando a nacionalidade e o domicílio de seus associados. Em caso de emergência, o art. 146 acima citado arma o poder público de remédios eficazes.

Atrair capital estrangeiro não quer dizer atrair estrangeiros para o Brasil. O que se quer é a cooperação financeira, necessária na fase atual da nossa evolução. Se, para isso, fôsse exigida a residência, aquela cooperação seria escassa, quase nula mesmo. Estaria prejudicada a finalidade do preceito constitucional, sem que para isso ocorressem motivos ponderáveis.

Com efeito. Do ponto de vista da segurança nacional, uma vez que a Constituição permite a participação de estrangeiros nas referidas emprêsas, pouco importaria que êles residissem ou não no Brasil. A fiscalização, a regulamentação é exercida sôbre a emprêsa, como pessoa jurídica brasileira, sujeita às sanções da lei brasileira.

Do ponto de vista econômico, a exigência de domicílio no país visaria sòmente evitar a saída de dividendos. Não é certo que o evitasse; mais certo, sem dúvida, é que não viessem capitais estrangeiros.

A estas razões específicas juntam-se as já aduzidas anteriormente, e tudo leva à conclusão de que não é necessário que o acionista estrangeiro resida no Brasil.

\section{ASPECTOS DO RECONHECIMENTO DA FILIAÇÃO ILEGÍTIMA}

Efeitos do ato ou da sentença que declara a filiação com base na Lei n. 883, de 21 de outubro de 1949, em relação à herança deferida antes da sua vigência.

\section{Sílvio Walace Duncan}

Tem-se dito e redito que, face ao preceito contido no artigo 1.577 do Código Civil, não podem os filhos ilegítimos alcançar a herança dos pais, se aberta a sucessão antes da vigência da lei permissiva do reconhecimento, eis que "a capacidade para suceder é a do tempo da abertura da sucessão, que se regulará conforme a lei então em vigor". Os que assim pensam, e são maioria no Brasil, afirmam que à solução contrária importaria na postergação do direito adquirido pelos herdeiros existentes ao tempo da abertura da sucessão, com se admitir efeito retroativo à lei que faculta o reconhecimento da filiação. Será exata a assertiva?

A matéria resume-se a uma questão de direito, objeto de renhida controvérsia. No País, tem foros de clássica a decisão do colendo Supremo Tribunal Federal, proferida, em grau de recurso de embargos, no caso da menor Colombina, que suscitou encômios ou censuras de eminentes juristas pátrios, consoante o ponto de vista adotado por uns e outros. Antes, a controvérsia apaixonara jurisconsultos de tomo, em França, ao se aplicar a lei de 16 de novembro de 1916. Em três sucessivos arestos, a Côrte de Cassação de Paris decidia que os filhos naturais reconhecidos podiam concorrer à sucessão dos respectivos pais, embora deferida antes de vigorar aquela lei. Esta solução, no entender do Tribunal Gaulês, não importava em ofensa aos direitos adquiridos pelos herdeiros existentes à época da abertura da sucessão, inobstante haver em França dispositivo idêntico ao do art. 1.577 do nosso Código, com proclamar que a capacidade para suceder é regulada pela lei em vigor no dia em que a sucessão se abre. 